\title{
Thyroid Dysfunction Caused by Second-Generation Tyrosine Kinase Inhibitors in Philadelphia Chromosome-Positive Chronic Myeloid Leukemia
}

\author{
Theo D. Kim, ${ }^{1}$ Michaela Schwarz, ${ }^{1}$ Hendrik Nogai, ${ }^{1}$ Peggy Grille${ }^{1}$, Jörg Westermann, ${ }^{1}$ Ursula Plöckinger, ${ }^{2}$ \\ Doreen Braun ${ }^{3}$, Ulrich Schweizer, ${ }^{3}$ Renate Arnold, ${ }^{1}$ Bernd Dörken, ${ }^{1}$ and Philipp le Coutre ${ }^{1}$
}

Background: Thyroid dysfunction is a well-known adverse effect of first-generation tyrosine kinase inhibitors (TKIs), like sunitinib. The aim of this study was to investigate the effect of second-generation TKIs on thyroid function.

Methods: We retrospectively assessed the effect of the first-generation TKI imatinib and the second-generation TKI nilotinib and dasatinib on thyroid function tests in 73 Philadelphia chromosome-positive (Ph-positive) chronic myeloid leukemia patients.

Results: Overall, 33 of 73 (45\%) had one or more thyroid function test abnormalities during follow-up. Hypothyroidism or hyperthyroidism were found in 18 of $73(25 \%)$ and 21 of $73(29 \%)$ cases after a median of 6 and 22 weeks, respectively. In most patients (29 of 39, 74\%) thyroid dysfunction was transient without clinical symptoms. Therapy of hypo-/hyperthyroidism was required in three patients. Thyroid dysfunction never resulted in the discontinuation of TKI therapy. Under treatment with imatinib, nilotinib, and dasatinib, thyroid abnormalities were detected in $25 \%, 55 \%$, and $70 \%$, respectively. Four of 55 patients $(7 \%)$ treated with nilotinib had evidence for an autoimmune thyroiditis (antibody positive in 3 of 4 patients) with an episode of hyperthyroidism preceding hypothyroidism.

Conclusions: Thyroid dysfunction is a common adverse event with second-generation TKI therapy in patients with Ph-positive chronic myeloid leukemia. Although the mechanism is still unclear, the high frequency of thyroid abnormalities, including autoimmune thyroiditis, warrants regular and long-term monitoring of thyroid function in these patients.

\section{Introduction}

$\mathbf{T}$

HYROID DYSFUNCTION, mostly hypothyroidism, is a wellrecognized side effect of treatment with tyrosine kinase inhibitors (TKIs) (1-3). Its incidence ranged from 53\% to $85 \%$ in retrospective and from $36 \%$ to $71 \%$ in prospective studies. Sunitinib malate, a multitargeted small-molecule TKI, has been reported to cause hypothyroidism in patients with metastatic renal cell carcinoma and gastrointestinal stromal tumors (4-6). Possible mechanisms include the induction of a destructive thyroiditis $(4,7,8)$, the inhibition of peroxidase activity (9), the blocking of iodine uptake (10), irreversible thyroid destruction (11), or capillary dysfunction $(9,12)$, targeting vascular endothelial growth factor (VEGF) receptors via its antiangiogenic activity. Due to the high incidence of hypothyroidism in patients treated with sunitinib, a routine control algorithm has recently been proposed (13). However, hypothyroidism does not require the interruption of treatment per se since replacement with levothyroxine seems to be effective $(5,6)$. In addition, thyroid dysfunction has also been described with sorafenib (14) and motesanib (15), though at much lower rates.

Several TKIs specifically target the oncogenic activity of the breakpoint cluster region (BCR)-agelson murine leukemia viral oncogene homolog (ABL) protein in patients with Philadelphia chromosome-positive (Ph-positive) chronic myeloid leukemia (CML) (16). The first-generation TKI imatinib mesylate is the standard of care and leads to durable remissions in the majority of patients in chronic phase (CP) CML (17). However, long-term results from the IRIS study (International Randomized Study of Interferon vs STI571) show that $>30 \%$ of patients with newly diagnosed CML-CP discontinue imatinib within 6 years (18). For patients with imatinib-resistance or -intolerance, two second-generation

${ }^{1}$ Clinic for Hematology and Oncology, ${ }^{2}$ Interdisciplinary Metabolic Center, and ${ }^{3}$ Institute for Experimental Endocrinology, CharitéUniversitätsmedizin Berlin, Berlin, Germany. 
TKIs, nilotinib and dasatinib, are currently approved $(19,20)$. Whereas nilotinib was rationally designed on the structural basis of imatinib for greater potency and specificity with respect to BCR-ABL inhibition $(21,22)$, dasatinib is a dual sarcoma (SRC)/ABL inhibitor with less stringent conformational requirements and a wider spectrum of targets (23). Clinically, both show considerable activity after imatinib failure $(24,25)$ and in previously untreated patients $(26,27)$.

It is unclear at present whether second-generation TKIs with increased specificity share the same adverse effects as first-generation TKIs like sunitinib and imatinib. Data on the incidence of thyroid dysfunction in patients treated with second-generation TKIs are not available. The current study therefore retrospectively investigated the incidence of thyroid dysfunction during therapy with the second-generation TKIs, nilotinib and dasatinib, in patients with CML-CP.

\section{Materials and Methods}

\section{Patients}

Between May 2005 and July 2009, 71 patients with Phpositive CML in CP $(n=67)$, accelerated phase $(n=3)$, and hypereosinophilic syndrome $(n=1)$ were treated in our center with imatinib, nilotinib, and/or dasatinib as first-line, second-line, or, in rare instances, as third-line treatment. Most patients were treated within clinical trials (Clinicaltrials.gov: NCT00471497, NCT00109707, and NCT00905593). Patients gave their informed written consent to participate in a clinical trial or to have their data analyzed retrospectively. All procedures were followed in accordance with the Helsinki Declaration and were approved by the local ethics committee. Patients received imatinib $400 \mathrm{mg}$ qd, nilotinib $400 \mathrm{mg}$ bid, and/or dasatinib $100 \mathrm{mg}$ qd with dose reductions for toxicity and, in the case of imatinib, dose escalation for incomplete response as necessary. Patients were followed regularly every 3 to 6 months. Determination of disease stage and response criteria were done according to standard criteria (28).

\section{Evaluation of thyroid function}

Thyroid function tests (TFTs) at baseline and during followup included serum thyroid-stimulating hormone (TSH), free triiodotyronine (fT3), and free thyroxine (fT4). In four cases antibodies against thyroid peroxidase (TPOAb), thyroglobulin $(\mathrm{TgAb})$, and the TSH receptor (TRAb) were determined due to the development of hypothyroidism that was preceded by an episode of hyperthyroidism during follow-up (see below). Serum TSH, fT3, and fT4 were measured by an electrochemiluminescent immunoassay (ECLIA; Roche, GrenzachWyhlen, Germany); TPOAb and TgAb by an luminescence immunoassay with time-resolved amplified cryptate emission (TRACE) technology (Brahms, Hennigsdorf, Germany); and TRAb by a electrochemiluminescent receptor assay (Elecsys ${ }^{\circledR}$; Roche). Serum samples were collected, handled, and analyzed according to internal standard operating procedures. Laboratory reference ranges are $0.27-4.20 \mathrm{mU} / \mathrm{L}$ for $\mathrm{TSH}$, 2.6-5.1 ng/L for fT3, and 0.9-1.9 ng/dL for fT4. Upper limits for antibody positivity were $>60 \mathrm{kU} / \mathrm{L}$ for $\mathrm{TgAb}$ and TPOAb, and $>1.8 \mathrm{IE} / \mathrm{L}$ for TRAb. Thyroid ultrasonography and Color Doppler ultrasonography were performed in four patients (see below).

\section{Definition of hypothyroidism and hyperthyroidism}

The biochemical diagnosis of subclinical hypothyroidism and hyperthyroidism was defined in accordance with the guidelines of the American Thyroid Association, the American Association of Clinical Endocrinologists and the Endocrine Society $(29,30)$. Subclinical hypothyroidism is defined as a serum TSH concentration above the upper limit of normal ( $4.20 \mathrm{mU} / \mathrm{L})$ with $\mathrm{fT} 4$ concentration within its reference range, and subclinical hyperthyroidism is defined as a serum TSH concentration below the lower limit of normal $(0.27 \mathrm{mU} / \mathrm{L})$ with fT4 and fT3 concentration within their reference ranges. Hyperthyroidism is defined as a serum TSH concentration below $0.1 \mathrm{mIU} / \mathrm{L}$ and serum fT 4 or fT3 concentrations above the normal reference range, and hypothyroidism is defined as a low serum fT4 concentration with elevated serum TSH concentration. Thyroid hormone replacement therapy and treatment with antithyroid medication was initiated at the discretion of the treating physician depending upon the clinical presentation. Patients with biochemical subclinical hypothyroidism or hypothyroidism and symptoms compatible with hypothyroidism (e.g., fatigue, cold intolerance, constipation, or weight gain) received thyroid hormone replacement therapy with levothyroxine. All patients with hyperthyroidism and symptoms compatible with hyperthyroidism (e.g., anxiety, weakness, tremor, palpitations, heat intolerance, increased perspiration, and weight loss, despite a normal or increased appetite and diarrhea) were treated with antithyroid medication.

\section{Results}

\section{Patient characteristics}

Overall, 64 of 71 patients had TFTs available (Table 1). For the purpose of this study, patients were allocated to three groups with 8,55, and 10 patients being treated with imatinib, nilotinib, and dasatinib, respectively. Since some patients sequentially received different TKIs, the sum of these three groups is higher than the number of actual patients. Median age was 57 years (range 25-85) and median follow-up 16 months (range 1-51). Eleven patients had a previous history of thyroid dysfunction with (partial) thyroidectomy in four cases, hypothyroidism in six cases, and goiter in one case. Nine patients were receiving levothyroxine therapy at study entry (eight for hypothyroidism and one for a goiter), of whom one was hyperthyroid, one had subclinical hyperthyroidism, and the remainder normal thyroid function. Twelve patients received medications known to potentially interfere with thyroid function (11 salicylates, 1 glucocorticoids, and 1 amiodarone), of whom 1 had subclinical hyperthyroidism and 1 subclinical hypothyroidism. None had received radioiodine therapy or external neck irradiation. Median disease duration of CML was 29 months (range 0-218). Before imatinib, nilotinib, and dasatinib, $0 / 8$ (0\%), 18/55 (33\%), and $3 / 10(30 \%)$ had received interferon, respectively.

\section{TFTs during TKI therapy}

At baseline, median TSH was $1.33 \mathrm{mU} / \mathrm{L}$ (range 0.01-7.05). Ten patients had abnormal baseline TFTs: five had elevated TSH concentration, all with normal fT4 and fT3 values without treatment, and five had suppressed TSH concentrations, with four patients having normal fT4 and fT3 values without 
Table 1. Patient Characteristics

\begin{tabular}{|c|c|c|c|c|}
\hline & Total & Imatinib & Nilotinib & Dasatinib \\
\hline$n$ & 73 & 8 & 55 & 10 \\
\hline Male & 36 & 5 & 27 & 4 \\
\hline Female & 37 & 3 & 28 & 6 \\
\hline Median age (range) & $57(25-85)$ & $45.5(28-70)$ & $61(25-85)$ & $57.5(26-73)$ \\
\hline Follow-up (days, range) & $500(20-1547)$ & $201(112-594)$ & $595(104-1547)$ & $412(20-687)$ \\
\hline \multicolumn{5}{|l|}{ Disease/indication } \\
\hline CML-CP & $66(90)$ & 8 & 51 & 7 \\
\hline CML-AP & $6(8)$ & 0 & 3 & 3 \\
\hline HES & $1(1)$ & 0 & 1 & 0 \\
\hline Median disease duration (months, range) & $29(0-218)$ & $1(0-1)$ & $32(0-180)$ & $56.5(0-218)$ \\
\hline \multicolumn{5}{|l|}{ Previous treatment } \\
\hline HU (\%) & $62(85)$ & $5(63)$ & $48(87)$ & $9(90)$ \\
\hline IFN (\%) & $21(29)$ & 0 & $18(33)$ & $3(30)$ \\
\hline Other $(\%)$ & $16(22)$ & 0 & $13(24)$ & $3(30)$ \\
\hline SCT (\%) & $1(1)$ & 0 & $1(2)$ & 0 \\
\hline Imatinib (\%) & $49(67)$ & NA & $40(73)$ & $9(90)$ \\
\hline Nilotinib (\%) & $7(10)$ & 0 & NA & $7(70)$ \\
\hline Dasatinib (\%) & 0 & 0 & 0 & NA \\
\hline Thyroid history before TKIs ${ }^{a}$ & $11(15)$ & $1(13)$ & $7(13)$ & $3(30)$ \\
\hline Thyroid medication before TKIs ${ }^{\mathrm{b}}$ & $9(12)$ & $1(13)$ & $6(11)$ & $2(20)$ \\
\hline \multicolumn{5}{|l|}{ Baseline TFT } \\
\hline TSH (median, range) & $1.33(0.01-7.05)$ & $2.36(1.24-4.28)$ & $1.1(0.01-7.05)$ & $1.39(0.7-4.46)$ \\
\hline Normal thyroid function & $63(86)$ & $7(88)$ & $48(87)$ & $8(80)$ \\
\hline Hypothyroidism & $5(7)$ & $1(13)$ & $2(4)$ & $2(20)$ \\
\hline Hyperthyroidism & $5(7)$ & 0 & $5(9)$ & 0 \\
\hline
\end{tabular}

a Partial thyroidectomy $(n=4)$, hypothyroidism $(n=6)$, and goiter $(n=1)$.

${ }^{\mathrm{b}}$ All levothyroxine.

$\mathrm{AP}$, accelerated phase; CML, chronic myeloid leukemia; CP, chronic phase; HES, hypereosinophilic syndrome; HU, hydroxyurea; IFN, interferon alpha; NA, not applicable; SCT, stem cell transplantation; TFT, thyroid function test; TKI, tyrosine kinase inhibitor; TSH, thyroidstimulating hormone.

treatment and one patient having increased fT4 under levothyroxine substitution therapy. Sixty-three of 73 patients $(86 \%)$ were euthyroid at baseline (Table 1$)$. During the study period, 40 of 73 patients (55\%) had normal thyroid function, whereas 33 of 73 patients (45\%) had one or more TFT abnormalities (Table 2). Eighteen (25\%) and 21 patients (29\%) of 73 patients had hypothyroidism and hyperthyroidism, respectively. Mean TFTs were similar when analyzed at 3, 6, and 12 months (Fig. 1).

\section{Time course and clinical management of abnormal thyroid function}

Most cases of hypothyroidism (11 of $17,65 \%)$ or hyperthyroidism ( 13 of $21,62 \%$ ) were transient with 6 and 4 patients developing persistent hypothyroidism or hyperthyroidism, respectively (Table 3 ). Hyperthyroidism was detected relatively early after a median of 6 weeks (range 1-70), whereas hypothyroidism occurred after a median of 22 weeks (range 1-135). Clinically, there were only three instances of signs and symptoms possibly related to hyperthyroidism. Two cases of diarrhea, and one case of atrial fibrillation. The latter had had a history of paroxysmal atrial fibrillation for 20 years and had a single brief self-limiting episode 2 months after the initiation of treatment. None received antithyroid treatment. One patient on nilotinib was briefly being treated with methimazole before developing transient hypothyroidism (see below), and two hypothyroid patients started levothyroxine. One of these two patients was under amiodarone with slightly elevated TSH at baseline and levothyroxine was initiated when taking dasatinib. Of the 10 patients with a previous history of thyroid dysfunction receiving thyroid medication, only one had his

Table 2. Thyroid Function Test Abnormalities During Tyrosine Kinase Inhibitor Therapy

\begin{tabular}{lrrrr}
\hline & Total & Imatinib & Nilotinib & Dasatinib \\
\hline Normal thyroid function (\%) & $40(55)$ & $6(75)$ & $30(55)$ & $4(40)$ \\
Hypothyroidism (\%) & $18(25)$ & $1(13)$ & $12(22)$ & $5(50)$ \\
$\quad$ Subclinical (\%) & $11(15)$ & $1(13)$ & 0 & $6(11)$ \\
Clinical (\%) & $7(10)$ & $1(13)$ & $18(33)$ & $4(40)$ \\
Hyperthyroidism (\%) & $21(29)$ & $1(13)$ & $10(18)$ & $2(20)$ \\
Subclinical (\%) & $13(18)$ & 0 & $8(15)$ & $2(20)$ \\
Clinical (\%) & $8(11)$ & & 0 \\
\hline
\end{tabular}

Patients can have more than one abnormality. 


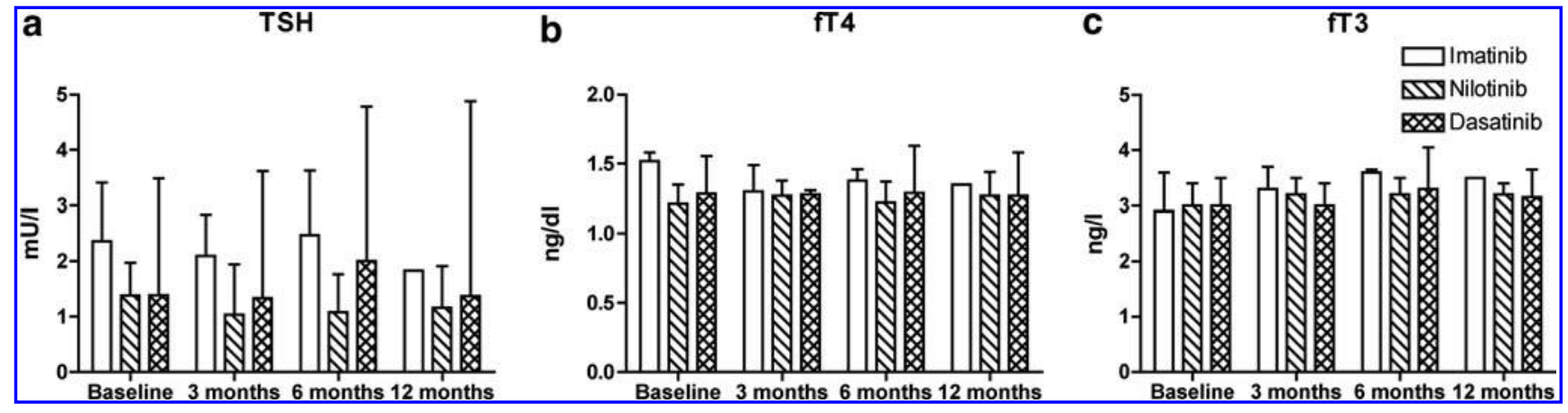

FIG. 1. (a) TSH, (b) fT4, and (c) fT3 levels during treatment with imatinib $(n=8)$, nilotinib $(n=55)$, and dasatinib $(n=10)$. Shown are baseline and follow-up values at 3, 6, and 12 months after initiation of the tyrosine kinase inhibitor. fT3, free triiodotyronine; fT4, free thyroxine; TSH, Thyroid-stimulating hormone.

levothyroxine stopped, whereas all others continued their treatment without any change in thyroid hormone or TSH concentration during therapy. Among the 21 patients who had previously received interferon, 5 had hypothyroidism (2 subclinical and 3 clinical), and 9 had hyperthyroidism (6 subclinical and 3 clinical). Although these abnormalities were slightly more common as compared to all other patients, this was not statistically significant.

\section{Drug-induced thyroiditis during TKI therapy}

Of 18 patients with hypothyroidism during follow-up, 4, all being treated with nilotinib, had a preceding episode of hyperthyroidism (Fig. 2 and Table 3). Hyperthyroidism occurred after a median 19 weeks (range 44-378), and hypothyroidism after a median of 35 weeks (range 112-420). TgAb were detected in three of four patients $(28,192.6$, and $683.2 \mathrm{kU} / \mathrm{L})$ and TPOAb in one of four $(680 \mathrm{kU} / \mathrm{L})$. The fourth patient had no thyroid autoantibodies when assessed for the first time $>3$ years after this episode. All four patients had sonographic abnormalities, with two patients having hypoechoic areas and two having multiple nodules. Clinically, hypothyroidism resolved spontaneously in three of these patients, and one patient was started on levothyroxine due to clinical overt hypothyroidism. However, since follow-up is short in this patient, a transient state cannot be excluded.

\section{Discussion}

Thyroid dysfunction is a well-known adverse effect of first-generation TKI therapy (1-3). Athyroid patients with CML $(31,32)$ or metastatic medullary thyroid carcinoma (33) simultaneously being treated with thyroid hormones and imatinib seem to need a significant increase of the levothyroxine replacement dose. Increased nondeiodination clearance through enzyme induction has been proposed as a potential mechanism (32). However, there was no thyroid dysfunction in patients with the thyroid in situ (34).

Here, we analyzed thyroid function through serial monitoring of TFTs in patients being treated with imatinib, nilotinib, and dasatinib. To avoid the potential influence of comorbidities as well as the influence of CML cells and intensive treatment regimens on thyroid function, only patients with CML in chronic or early accelerated phase and one patient with hypereosinophilic syndrome were included in the present study

Thyroid abnormalities were very common with only about a third of the population being strictly euthyroid during follow-up. Both hypothyroidism and hyperthyroidism were each found in about a quarter of patients. However, these changes were mostly subclinical and transient and, according to the American Thyroid Association guidelines (30), rarely needed any treatment. Due to the transient nature of druginduced hypo- or hyperthyroidism, as well as the mild clinical course with lack of symptoms in all but two patients, no specific treatment was initiated. The therapeutic relevance of early diagnosis of hypothyroidism or hyperthyroidism is therefore unclear. Due to the retrospective nature of this study, more detailed analyses of mechanisms were not possible. However, 4 of 18 patients (22\%) with hypothyroidism and 4 of 55 patients $(7 \%)$ being treated with nilotinib had evidence for an autoimmune thyroiditis, which, however, did not lead to persistent hypothyroidism. Only one of these four

Table 3. Kinetics of Thyroid Function Test Abnormalities

\begin{tabular}{|c|c|c|c|c|}
\hline & Total & Imatinib & Nilotinib & Dasatinib \\
\hline Hypothyroidism (\%) & $18(25)$ & $1(13)$ & $12(22)$ & $5(50)$ \\
\hline Transient & $12(16)$ & $1(13)$ & $8(15)$ & $3(30)$ \\
\hline Persistent & $6(8)$ & 0 & $4(7)$ & $2(20)$ \\
\hline Median time to abnormal TSH (weeks, range) & 154 (7-944) & 7 & $248(22-944)$ & $142(7-370)$ \\
\hline Hyperthyroidism (\%) & $21(29)$ & $1(13)$ & $18(33)$ & $2(20)$ \\
\hline Transient & $17(23)$ & $1(13)$ & $15(27)$ & $1(10)$ \\
\hline Persistent & $4(5)$ & 0 & $3(5)$ & $1(10)$ \\
\hline Median time to abnormal TSH (weeks, range) & $44(7-488)$ & 480 & $43(6-488)$ & $41.5(19-64)$ \\
\hline Hypothyroidism with previous hyperthyroidism & $4(5)$ & 0 & $4(7)$ & 0 \\
\hline Hypothyroidism without previous hyperthyroidism & $14(19)$ & $1(13)$ & $8(15)$ & $5(50)$ \\
\hline
\end{tabular}




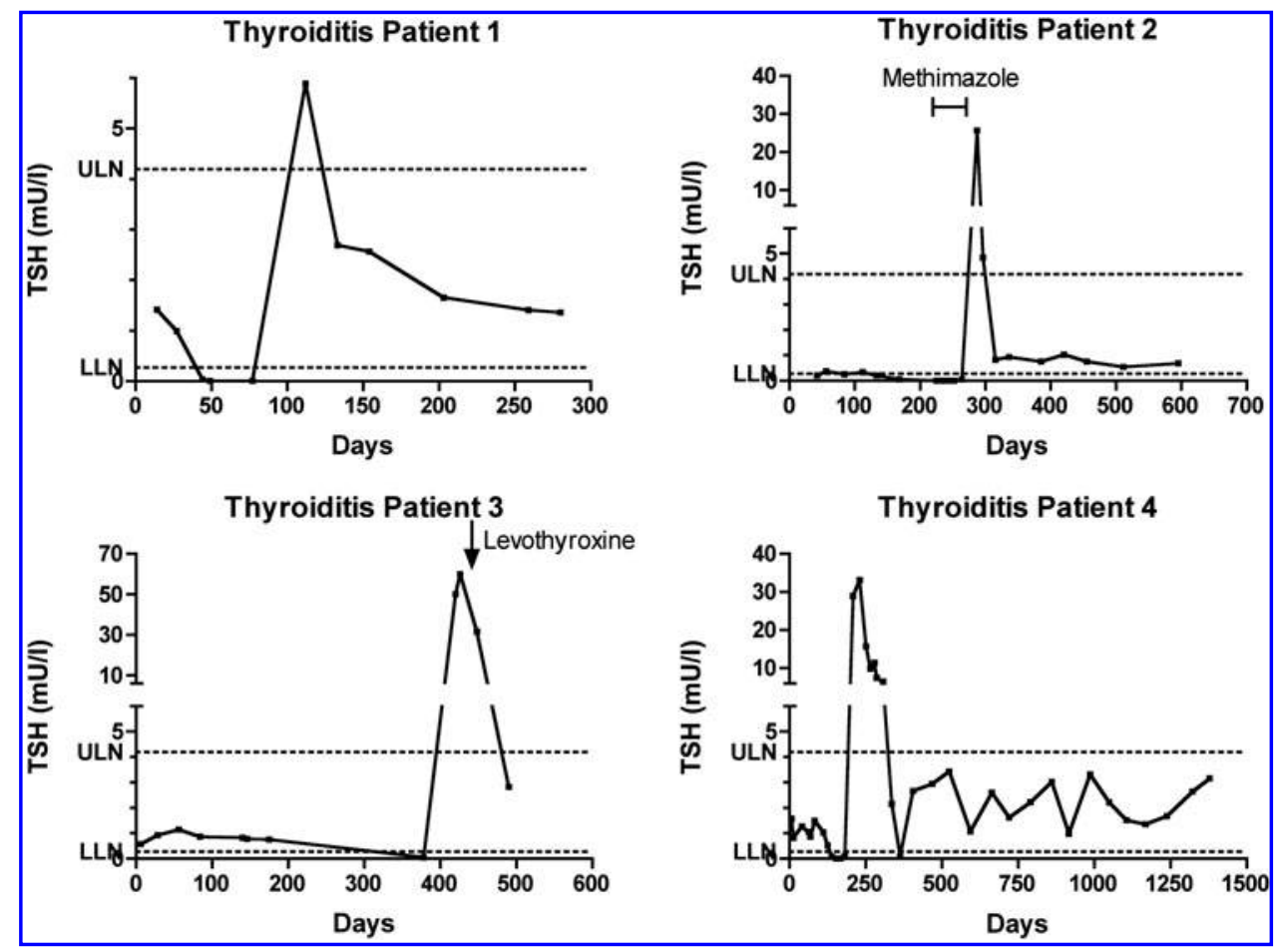

FIG. 2. Hyperthyroidism preceding hypothyroidism in four patients treated with nilotinib. Shown are changes in TSH levels during therapy with nilotinib. Patient 2 needed brief antithyroid treatment with methimazole. Patient 3 is under levothyroxine substitution at last follow-up. LLN, lower limit of normal; ULN, upper limit of normal.

patients, who did not have autoantibodies, had previously been treated with interferon arguing against cytokine-induced generation of autoantibodies as a major factor.

In conclusion, we found thyroid dysfunction to be common in patients with Ph-positive CML under treatment with imatinib and the second-generation TKIs, nilotinib and dasatinib. However, these abnormalities rarely implied a change in clinical management or required treatment, and never led to discontinuation of the TKI. Due to the inherent limitations of a retrospective, uncontrolled study and the sample size of our cohort no direct comparisons between different drug therapies is possible. Nevertheless, the frequency of thyroid abnormalities and occurrence of cases with evidence for thyroiditis indicates that these patients should be monitored regularly. Despite their reported kinase specificity, TKIs share still elusive off-target effects that frequently result in abnormal TFTs, including autoimmune thyroiditis. We therefore suggest careful monitoring of TFTs in second-generation TKI-treated patients.

\section{Disclosure Statement}

P.1.C. received honoraria from Novartis. All other authors declare no competing financial interests.

\section{References}

1. Hershman JM, Liwanpo L 2010 How does sunitinib cause hypothyroidism? Thyroid 20:243-244.

2. Illouz F, Laboureau-Soares S, Dubois S, Rohmer V, Rodien P 2009 Tyrosine kinase inhibitors and modifications of thyroid function tests: a review. Eur J Endocrinol 160:331-336.

3. Torino F, Corsello SM, Longo R, Barnabei A, Gasparini G 2009 Hypothyroidism related to tyrosine kinase inhibitors: an emerging toxic effect of targeted therapy. Nat Rev Clin Oncol 6:219-228.

4. Desai J, Yassa L, Marqusee E, George S, Frates MC, Chen $\mathrm{MH}$, Morgan JA, Dychter SS, Larsen PR, Demetri GD, Alexander EK 2006 Hypothyroidism after sunitinib treatment for patients with gastrointestinal stromal tumors. Ann Intern Med 145:660-664.

5. Rini BI, Tamaskar I, Shaheen P, Salas R, Garcia J, Wood L, Reddy S, Dreicer R, Bukowski RM 2007 Hypothyroidism in patients with metastatic renal cell carcinoma treated with sunitinib. J Natl Cancer Inst 99:81-83.

6. Wolter P, Stefan C, Decallonne B, Dumez H, Bex M, Carmeliet P, Schoffski P 2008 The clinical implications of sunitinib-induced hypothyroidism: a prospective evaluation. $\underline{\mathrm{Br} J}$ Cancer 99:448-454.

7. Faris JE, Moore AF, Daniels GH 2007 Sunitinib (sutent)induced thyrotoxicosis due to destructive thyroiditis: a case report. Thyroid 17:1147-1149.

8. Grossmann M, Premaratne E, Desai J, Davis ID 2008 Thyrotoxicosis during sunitinib treatment for renal cell carcinoma. Clin Endocrinol (Oxf) 69:669-672.

9. Wong E, Rosen LS, Mulay M, Vanvugt A, Dinolfo M, Tomoda C, Sugawara M, Hershman JM 2007 Sunitinib induces hypothyroidism in advanced cancer patients and may inhibit thyroid peroxidase activity. Thyroid 17:351-355.

10. Mannavola D, Coco P, Vannucchi G, Bertuelli R, Carletto M, Casali PG, Beck-Peccoz P, Fugazzola L 2007 A novel tyrosine-kinase selective inhibitor, sunitinib, induces transient hypothyroidism by blocking iodine uptake. I Clin Endocrinol Metab 92:3531-3534.

11. Rogiers A, Wolter P, Op de Beeck K, Thijs M, Decallonne B, Schoffski P 2010 Shrinkage of thyroid volume in sunitinibtreated patients with renal-cell carcinoma: a potential marker of irreversible thyroid dysfunction? Thyroid 20:317-322. 
12. Makita N, Miyakawa M, Fujita T, Iiri T 2010 Sunitinib induces hypothyroidism with a markedly reduced vascularity. Thyroid 20:323-326.

13. Wolter $\mathrm{P}$, Stefan $\mathrm{C}$, Decallonne B, Dumez H, Fieuws $\mathrm{S}$, Wildiers $\mathrm{H}$, Clement $\mathrm{P}$, Debaere $\mathrm{D}$, Van Oosterom A, Schoffski P 2008 Evaluation of thyroid dysfunction as a candidate surrogate marker for efficacy of sunitinib in patients (pts) with advanced renal cell cancer (RCC). I Clin Oncol (Meeting Abstracts) 26:5126.

14. Tamaskar I, Bukowski R, Elson P, Ioachimescu AG, Wood L, Dreicer R, Mekhail T, Garcia J, Rini BI 2008 Thyroid function test abnormalities in patients with metastatic renal cell carcinoma treated with sorafenib. Ann Oncol 19:265-268.

15. Sherman SI, Wirth LJ, Droz JP, Hofmann M, Bastholt L, Martins RG, Licitra L, Eschenberg MJ, Sun YN, Juan T, Stepan DE, Schlumberger MJ 2008 Motesanib diphosphate in progressive differentiated thyroid cancer. $\mathrm{N}$ Engl J Med 359:31-42

16. Druker BJ 2008 Translation of the Philadelphia chromosome into therapy for CML. Blood 112:4808-4817.

17. Hehlmann R, Hochhaus A, Baccarani M 2007 Chronic myeloid leukaemia. Lancet 370:342-350.

18. Hochhaus A, O'Brien SG, Guilhot F, Druker BJ, Branford S, Foroni L, Goldman JM, Muller MC, Radich JP, Rudoltz M, Mone M, Gathmann I, Hughes TP, Larson RA 2009 Six-year follow-up of patients receiving imatinib for the first-line treatment of chronic myeloid leukemia. Leukemia 23:1054-1061.

19. Hantschel O, Rix U, Superti-Furga G 2008 Target spectrum of the BCR-ABL inhibitors imatinib, nilotinib and dasatinib. Leuk Lymphoma 49:615-619.

20. Weisberg E, Manley PW, Cowan-Jacob SW, Hochhaus A, Griffin JD 2007 Second generation inhibitors of BCR-ABL for the treatment of imatinib-resistant chronic myeloid leukaemia. Nat Rev Cancer 7:345-356.

21. Manley PW, Drueckes P, Fendrich G, Furet P, Liebetanz J, Martiny-Baron G, Mestan J, Trappe J, Wartmann M, Fabbro D 2010 Extended kinase profile and properties of the protein kinase inhibitor nilotinib. Biochim Biophys Acta 1804:445453.

22. Weisberg E, Manley PW, Breitenstein W, Bruggen J, CowanJacob SW, Ray A, Huntly B, Fabbro D, Fendrich G, HallMeyers E, Kung AL, Mestan J, Daley GQ, Callahan L, Catley L, Cavazza C, Azam M, Neuberg D, Wright RD, Gilliland DG, Griffin JD 2005 Characterization of AMN107, a selective inhibitor of native and mutant Bcr-Abl. Cancer Cell 7:129-141.

23. Shah NP, Tran C, Lee FY, Chen P, Norris D, Sawyers CL 2004 Overriding imatinib resistance with a novel ABL kinase inhibitor. Science 305:399-401.

24. Kantarjian H, Giles F, Wunderle L, Bhalla K, O'Brien S, Wassmann B, Tanaka C, Manley P, Rae P, Mietlowski W, Bochinski K, Hochhaus A, Griffin JD, Hoelzer D, Albitar M, Dugan M, Cortes J, Alland L, Ottmann OG 2006 Nilotinib in imatinib-resistant CML and Philadelphia chromosome-positive ALL. N Engl J Med 354:2542-2551.

25. Talpaz M, Shah NP, Kantarjian $\mathrm{H}$, Donato N, Nicoll J, Paquette R, Cortes J, O’Brien S, Nicaise C, Bleickardt E,
Blackwood-Chirchir MA, Iyer V, Chen TT, Huang F, Decillis AP, Sawyers CL 2006 Dasatinib in imatinib-resistant Philadelphia chromosome-positive leukemias. $\mathrm{N}$ Engl J Med 354:2531-2541.

26. Saglio G, Kim DW, Issaragrisil S, le Coutre $P$, Etienne $G$, Lobo C, Pasquini R, Clark RE, Hochhaus A, Hughes TP, Gallagher N, Hoenekopp A, Dong M, Haque A, Larson RA, Kantarjian HM 2010 Nilotinib versus imatinib for newly diagnosed chronic myeloid leukemia. N Engl J Med 362: 2251-2259.

27. Kantarjian H, Shah NP, Hochhaus A, Cortes J, Shah S, Ayala M, Moiraghi B, Shen Z, Mayer J, Pasquini R, Nakamae H, Huguet F, Boque C, Chuah C, Bleickardt E, Bradley-Garelik MB, Zhu C, Szatrowski T, Shapiro D, Baccarani M 2010 Dasatinib versus imatinib in newly diagnosed chronic-phase chronic myeloid leukemia. N Engl J Med 362:2260-2270.

28. Kim TD, Dörken B, le Coutre P 2008 Nilotinib for the treatment of chronic myeloid leukemia. Expert Rev. Hematol 1:29-39.

29. Surks MI, Chopra IJ, Mariash CN, Nicoloff JT, Solomon DH 1990 American Thyroid Association guidelines for use of laboratory tests in thyroid disorders. JAMA 263:1529 1532.

30. Surks MI, Ortiz E, Daniels GH, Sawin CT, Col NF, Cobin RH, Franklyn JA, Hershman JM, Burman KD, Denke MA, Gorman C, Cooper RS, Weissman NJ 2004 Subclinical thyroid disease: scientific review and guidelines for diagnosis and management. JAMA 291:228-238.

31. de Groot JW, Links TP, van der Graaf WT 2006 Tyrosine kinase inhibitors causing hypothyroidism in a patient on levothyroxine. Ann Oncol 17:1719-1720.

32. de Groot JW, Zonnenberg BA, Plukker JT, van Der Graaf WT, Links TP 2005 Imatinib induces hypothyroidism in patients receiving levothyroxine. Clin Pharmacol Ther 78: 433-438.

33. de Groot JW, Zonnenberg BA, van Ufford-Mannesse PQ, de Vries MM, Links TP, Lips CJ, Voest EE 2007 A phase II trial of imatinib therapy for metastatic medullary thyroid carcinoma. I Clin Endocrinol Metab 92:3466-3469.

34. Dora JM, Leie MA, Netto B, Fogliatto LM, Silla L, Torres F, Maia AL 2008 Lack of imatinib-induced thyroid dysfunction in a cohort of non-thyroidectomized patients. Eur J Endocrinol 158:771-772.

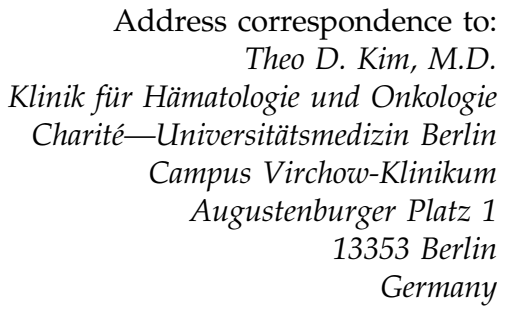

E-mail: theo.kim@charite.de 